\title{
INCLUSÃO ESCOLAR: histórico e análise das garantias legais da pessoa com deficiência
}

\author{
Vanessa Alves Pereira ${ }^{1}$ \\ ${ }^{1}$ Centro Universitário de Mineiros (UNIFIMES-GO), Mineiros, GO, Brasil.
}

\begin{abstract}
Resumo: Este estudo aborda sobre as garantias legais da pessoa com deficiência no contexto escolar. Tem como objetivo investigar os aparatos positivados e vigentes no Brasil sobre essa temática, bem como a análise da construção desse processo histórico-cultural no país. Para isso, esse artigo será tido de forma qualitativa voltada para uma revisão bibliográfica do processo de constituição da inclusão na perspectiva da escola inclusiva, acerca de seu conceito, definições sobre a pessoa com deficiência, direitos, leis e convenções internacionais que influenciaram a legislação brasileira sobre educação especial, de modo a contribuir com a superação de obstáculos e desafios desse processo, por meio da conscientização dos deveres do Estado para com a população, podendo assim verificar-se quais fatores criam barreiras nesse processo. Dentre as análises citadas, destacam-se um breve histórico sobre a origem e estruturação do processo de inclusão, uma trajetória das previsões constitucionais ao longo dos anos sobre a educação especial no Brasil. Para tanto, foram investigadas importantes prescrições oficiais, como: a Conferência Mundial de Educação para Todos e referentes às Estruturas de Ação em Educação Especial, adotadas pela Conferência Mundial em Educação Especial, as quais geraram a Declaração de Salamanca, em conjunto com a Convenção sobre os Direitos das Pessoas com Deficiência e o respectivo Protocolo Facultativo. Foi realizado um estudo sobre as garantias legais dos direitos da pessoa com deficiência no processo educacional, em consonância com os princípios da igualdade e dignidade da pessoa humana, como preconiza a Constituição Federal de 1988. Destaca-se as inovações comtempladas pela Lei Brasileira de Inclusão de 2015, tais como a criminalização de condutas que sejam discriminatórias.
\end{abstract}

Palavras-chave: Inclusão escolar. Garantias legais. Pessoa com deficiência.

\begin{abstract}
This study addresses the legal guarantees of people with disabilities in the school context. It aims to investigate the positive and current devices in Brazil on this theme, as well as the analysis of the construction of this historical-cultural process in the country. For this, this article will be had in a qualitative way aimed at a bibliographic review of the process of constituting inclusion from the perspective of the inclusive school, about its concept, definitions about the person with disabilities, rights, laws and international conventions that influenced Brazilian legislation on special education, in order to contribute to overcoming obstacles and challenges in this process, by raising awareness of the State's duties towards the population, thus being able to verify which factors create barriers in this process. Among the aforementioned analyzes, we highlight a brief history of the origin and structuring of the inclusion process, a trajectory of constitutional forecasts over the years on special education in Brazil. To this end, important official prescriptions were investigated, such as: the World Conference on Education for All and those referring to the Structures of Action in Special Education, adopted by the World Conference on Special Education, which generated the Salamanca Declaration, together with the Convention on the Rights of Persons with Disabilities and the Optional Protocol. A study was carried out on the legal guarantees of the rights of people with disabilities in the educational process, in line with the principles of equality and dignity of the human person, as recommended by the Federal Constitution of 1988. The innovations contemplated by the Brazilian Inclusion Law are highlighted. 2015, such as the criminalization of conduct that is discriminatory.
\end{abstract}

Keywords: School inclusion. Legal guarantees. Disabled person.

Como citar: PEREIRA, V. A. Inclusão Escolar: histórico e análise das garantias legais da pessoa com deficiência. Revista Científica Novas Configurações - Diálogos Plurais, Luziânia, v. 1, n.1, p. 21-33, 2020. https://doi.org/.10.4322/2675-4177.2020.004

\footnotetext{
Apoio financeiro: Nenhum.

Conflitos de interesses: Os autores declaram não haver nenhum conflito de interesse.

Correspondência: vanessa.alves@unifimes.edu.br

Recebido: 30 Mar 2020

Aprovado: 12 Mai 2020

Editor: Marcelo Máximo Purificação.
}

Este é um artigo publicado em acesso aberto (Open Access) sob a licença Creative Commons Attribution, que permite uso, distribuição e reprodução em qualquer meio, sem restrições desde que o trabalho original seja corretamente citado. 


\section{INTRODUÇÃO}

A inclusão social tem sido um tema bastante discutido na atualidade, mas a realidade é que pequena parcela da sociedade sabe de fato o que seria essa "inclusão", mesmo sendo um direito do cidadão, fazendo parte das políticas públicas no Brasil, de princípios constitucionais, como a igualdade e a dignidade da pessoa humana, é de dever do Estado efetivar as garantias individuais e sociais do cidadão em sua amplitude de uma sociedade justa, livre e solidária, como preconiza o artigo $3^{\circ}$ da Constituição Federal.

Inicialmente será necessário definir o que seria a "inclusão", sendo que, para MRECH (1998), a sociedade deve proporcionar espaços para que todos os cidadãos possam ter as mesmas oportunidades no que tange a ter acesso à educação de forma participativa, respeitando as características individuais de cada um, com o princípio da igualdade entre as pessoas.

O foco é analisar o direito constitucional e infraconstitucional da pessoa com necessidade especial no ambiente escolar, direito esse assegurado no artigo 205 da Constituição Federal que define a educação como direito de todos e assegura o atendimento educacional especializado, bem como refletir sobre o modo como as legislações internacionais influenciaram o sistema jurídico brasileiro a respeito da temática, por meio da pesquisa qualitativa.

A Constituição de 1988 foi também chamada de "Constituição cidadã", pois, consagrou direitos aos grupos sociais que eram até então deixados à margem da sociedade, como era o caso da pessoa com algum tipo de deficiência. Além disso, será feita uma breve análise dos tratados e convenções internacionais sobre a temática, legislações vigentes no Brasil, tais como a Lei Brasileira de Inclusão e suas inovações.

\section{ORIGEM HISTÓRICA DA INCLUSÃO, RELACIONADO À PESSOA COM DEFICIÊNCIA.}

Conceitua-se inclusão social como um processo pelo qual a sociedade se adapta para incluir em seus sistemas sociais todas as pessoas que tem alguma necessidade especial e simultaneamente visa prepará-las para assumir posições na sociedade, encontrando caminhos propícios para seu desenvolvimento através da educação e qualificação. Portanto, a inclusão social é um processo de transformações tanto físicas quanto culturais (SASSAKI, 1997).

Além das barreiras físicas citadas acima, é importante salientar que a inclusão também engloba a necessidade de um processo de ruptura das várias barreiras atitudinais e comunicacionais existentes na sociedade, pois, estas também trazem grande impacto para a vida da pessoa com deficiência e sem as mesmas o processo de inclusão não é possível.

A inclusão social pode ser definida como um conjunto de meios e ações que buscam combater a exclusão dos direitos da vida em sociedade, exclusão essa que pode ocorrer por diversos fatores como: por classe social, origem geográfica, educação, idade, sexo, deficiência, étnico-raciais, cunho religioso, orientação sexual, dentre outros. Dessa forma o objetivo da inclusão seria tornar a sociedade um lugar acessível para todos os cidadãos, indiscriminadamente, para usufruir de seus direitos e desenvolver suas potencialidades (CARVALHO; SILVA, 2012).

Porém, para que esse conjunto de ações sejam concretizadas seria necessária a idealização de um processo a ser implantado, primeiramente, no âmbito jurídico, e no meio social, por todos os indivíduos, como veremos mais adiante.

A deficiência sempre foi vista por meio do misticismo e ocultismo, enraizada a conceitos religiosos e castigos divinos, que impediam estudos de base científica para o desenvolvimento de questões realísticas sobre a temática, isso contribuiu para que as pessoas com necessidades especiais fossem ignoradas e marginalizadas, sendo a inclusão social estruturada em quatro fases: exclusão, segregação, integração e inclusão. No passado o indivíduo que possuía algum comprometimento era banido da sociedade e até mesmo sacrificado (MAZZOTTA, 2005).

A civilização egípcia é considerada uma das mais antigas da humanidade e possui inúmeros vestígios de pessoas com deficiência, registros esses identificados por meio do papiro. Na cultura grega também foram encontrados vários registros de pessoas que possuíam alguma deficiência, tanto é, que seus deuses eram relatados de tal forma, com cegueiras ou alguma supressão física, sendo isso visto como castigo dos deuses (GUGEL, 2007).

A comunidade egípcia, assim como grande parte das comunidades antigas, eram politeístas e como não havia ainda uma explicação biológica para a deficiência, era mais lógico para esses povos justificar a questão com "castigos divinos" e também sacrifícios.

Costa e Rodrigues (2017), salienta também que as sociedades primitivas, formadas por nômades, abandonavam as pessoas com deficiência pela questão da sobrevivência, pois, pessoas doentes e corpos 
com dificuldades de locomoção não teriam como enfrentar os obstáculos ocasionados pela mudança constante de localidade da qual esses povos viviam, evidenciando assim o processo de exclusão.

No contexto da educação especial, Mazzota (2006), afirma que o processo de educação das P.C.D's (pessoas com deficiência) teve início em 1620, na França, tendo como precursor Jean Paul Bonet, ao promover a tentativa de ensinar os surdos a falar. Essa afirmação nos faz perceber que existe uma distância de quase 400 anos da primeira "tentativa" de inclusão, até os dias atuais. Ou seja, quase quatro séculos de luta para que esse processo pudesse ser evidenciado nos dias de hoje.

Em 1848, os Estados Unidos passaram a oferecer oficialmente atendimento para as P.N.E's, termo que já caiu em desuso, (pessoas com necessidades especiais), dessa forma houve um crescimento do número de instituições que prestavam esse atendimento especializado, tanto nos Estados Unidos, como no Canadá, dando início também a classes especiais dentro de escolas regulares, para as crianças com alguma especificidade (MELO, 2011).

Ora, os Estados Unidos foram pioneiros em ofertar o atendimento educacional especializado, dando uma visão mundial para a questão, na época em que os demais países ainda não davam tanta visibilidade para a temática.

A questão da deficiência remonta desde a Idade Média, porém, no Brasil o atendimento às pessoas com deficiência deu-se apenas no século XIX, por conta do interesse de alguns educadores pelo atendimento educacional especializado, inspirados por experiências europeias e norte-americanas (MANTOAN, 2010).

Mais uma vez percebemos quanta influência o pioneirismo dos Estados Unidos exerceu no Brasil, pois, professores brasileiros viram o modelo que os norte-americanos estavam seguindo e decidiram implementa-lo no Brasil, mesmo que de maneira ainda discreta.

De acordo com os dados do Instituto Brasileiro de Geografia e Estatística, cerca de $24 \%$ da população brasileira possui algum tipo de deficiência, correspondendo esse número a aproximadamente 45 milhões de Pessoas com Deficiência, termo atual, (P.c.D’s) no país (IBGE, 2010).

Pode-se perceber, por meio dos dados estatísticos, que o país possui um número grande de pessoas com alguma deficiência, sendo assim necessário que a sociedade esteja preparada para receber todas essas pessoas em seu meio, sem qualquer tipo de discriminação ou preconceito. Assim, é preciso entender o motivo pelo qual existem legislações especificas a tratar dessa temática, isto é, pela dificuldade da sociedade em se tornar acessível e pela necessidade de termos aparatos legais para garantir esses direitos.

O movimento de inclusão social, tem como objetivo construir uma sociedade real e justa para todos os cidadãos, necessitando de alguns pressupostos, tais como: a celebração das diferenças; o direito de pertencer; a valorização da diversidade humana; a solidariedade humanitária; a igual importância das minorias e a cidadania com qualidade de vida (SASSAKI, 1997). Ao longo dos anos, conforme o amadurecimento da ideia sobre "inclusão", esse processo foi tomando um novo formato e evoluindo não só no âmbito social, mas, também no aspecto jurídico

\section{AS PREVISÕES CONSTITUCIONAIS AO LONGO DOS ANOS: DIREITO À EDUCAÇÃO ESPECIAL}

Inicialmente, pode-se afirmar que em todas as constituições brasileiras, desde a Constituição do Império no ano de 1824 até a atual Carta Magna de 1988, o direito à educação se fez presente, apesar dos enfoques, sejam eles de visão política ou econômica, de cada época, passando assim por consideráveis evoluções.

A Constituição de 1824, outorgada por Dom Pedro I, foi marcada por um forte período do liberalismo, se limitando a tratar da educação em apenas dois incisos do art. 179, garantindo a gratuidade da instrução primária a todos os cidadãos brasileiros e determinando a criação de colégios e universidades dentro do elenco dos direitos civis e políticos (BASTOS, 2002).

A Constituição de 1891, foi chamada de "Constituição da República dos Estados Unidos do Brasil", sob grande influência dos Estados Unidos. Esta foi a primeira Constituição republicana promulgada. No que tange a educação, dispôs na Seção II do Título IV, sobre a laicidade do ensino ministrado nos estabelecimentos públicos, mas se absteve a respeito de sua universalidade, gratuidade e obrigatoriedade (BRASIL, Constituição da República dos Estados Unidos do Brasil, 1891). Ou seja, apesar das grandes conquistas para o período, até o presente momento nenhuma das constituições havia universalizado o ensino em todos os níveis, no máximo seria gratuito para o primário e posteriormente esse ensino seria laico. 
O texto constitucional de 1934, traz reflexos de aspirações e conflitos daquele período da sociedade, porém, seria de curta duração. Inseriu um novo título, específico sobre a educação, família e cultura, contendo a clássica declaração de direitos e garantias individuais, e outro sobre ordem econômica e social (SILVA, 2010).

Assim como as demais, a Constituição de 1934, trouxe vertentes clássicas, como os direitos e garantias individuais, além de normas advindas da Constituição Alemã de Weimar, pois esta última exerceu muita influência sobre a Constituição Brasileira.

Acerca da família, cultura e educação, houveram avanços no sentido de universalizar a educação como um direito de todos e incluir a família como ente responsável, juntamente com o Estado, a proporcionar à educação para todos (BRASIL, Constituição da República dos Estados Unidos do Brasil, 1934).

A Carta Magna de 1937, foi outorgada, segundo Silva (2010), pela "nova ordem denominada Estado Novo", ocasionando grande retrocesso em relação a Constituição anterior, no que diz respeito à educação. Todavia, manteve o ensino primário, porém trazendo restrições quanto a gratuidade e atribuiu a responsabilidade primeiro a família, colocando o Estado em posição de mero colaborador.

Após a II Guerra Mundial, a Constituição Federal de 1946, faz tentativa de resgatar os direitos individuais, sendo a educação obrigatória e gratuita na instrução primária. Porém, quanto ao ensino médio e superior, colocou a responsabilidade do ensino para a família, o Estado apenas como ente subsidiário (BASTOS, 2010).

Em curto espaço de tempo, percebe-se como o Estado oscilou com relação a sua responsabilidade no direito à educação. Na maioria das vezes, até então, tentava se abster desse dever, colocando sempre a família como responsável, quando muito se dispunha estar como sujeito meramente auxiliar.

A Constituição de 1967, dispôs sobre a educação no art. 168, vejamos: “Art. 168 - A educação é direito de todos e será dada no lar e na escola; assegurada a igualdade de oportunidade, deve inspirar-se no princípio da unidade nacional e nos ideais de liberdade e de solidariedade humana. " (BRASIL, Constituição da República Federativa do Brasil, 1967).

A partir de uma análise hermenêutica, percebe-se que o art. 168 da CF/67, manteve o direito universal do ensino, porém, quanto ao ensino superior, estabeleceu critérios quanto a gratuidade, utilizando uma espécie de bolsas, que teriam de ser reembolsadas depois, conforme o $\S 3^{\circ}$, inciso III, do art.168.

Em 1969, entrou em vigor a Emenda Constitucional nº 1, provocando alterações na Constituição de 1967, onde muitos estudiosos discutem sobre essa emenda ter caráter de nova Constituição. A respeito disso, José Afonso salienta:

Teórica e tecnicamente, não se tratou de emenda, mas de nova constituição. A emenda só serviu como mecanismo de outorga, uma vez que verdadeiramente se promulgou texto integralmente reformulado, a começar pela denominação que se lhe deu: Constituição da República Federativa do Brasil, enquanto a de 1967 se chamava apenas Constituição do Brasil. (SILVA, 2010, p. 87).

Ou seja, apesar de ser uma emenda constitucional, o dispositivo em questão reformulou indistintamente a Constituição de 1967, inclusive moldou o seu título, que viria a ser usado posteriormente na Constituição da República Federativa do Brasil de 1988.

No que tange à educação, a emenda em questão manteve basicamente todos os dispositivos que a constituição anterior previa, inovando apenas no reconhecimento, pela primeira vez, no dever do Estado em garantir a universalização do ensino (BRASIL. EC n.1/1969, art. 176).

As bolsas estudantis que haviam sido instituídas pela $\mathrm{CF} / 67$, foram mantidas e estendidas ao ensino médio, não somente ao superior como anteriormente era previsto, além do aluno ter que apresentar efetivo aproveitamento e provar a falta de recursos econômicos. Sobre à educação especial, cabe destacar que somente com a Emenda $\mathrm{n}^{\circ} 01$ à Constituição de 1967, surgiu vagamente a referência ao direito à educação de pessoas com deficiência.

A legislação dispunha sobre a "educação dos excepcionais", no art. artigo 175, § 4: "Lei especial disporá sobre a assistência à maternidade, à infância e à adolescência e sobre a educação de excepcionais." (BRASIL, EC n.1/1969).

Mesmo com a inserção desse dispositivo, não ficou esclarecido como seria realizada essa "educação de excepcionais", por qual lei especial, muito menos de quem seria essa responsabilidade e a cargo de quem ficariam os custos ou se seria gratuita ao indivíduo.

Posteriormente, com a promulgação da emenda $n^{\circ} 12$, no ano de 1978, houve uma evolução considerável na proteção constitucional no direito à educação das pessoas com deficiência, onde fora 
assegurado uma educação especial gratuita com intuito de melhorar sua condição econômica e social (ARAÚJO, 1997).

Vejamos o artigo único, da Emenda $n^{\circ} 12$ :

Artigo único. É assegurado aos deficientes a melhoria de sua condição social e econômica especialmente mediante:

I - educação especial e gratuita;

II - assistência, reabilitação e reinserção na vida econômica e social do País; a salários;

III - proibição de discriminação, inclusive quanto à admissão ao trabalho ou ao serviço público e

IV - possibilidade de acesso a edifícios e logradouros públicos (BRASIL, EC nº 12, 1978).

Conforme o texto acima, fica perceptível que foram inseridos dispositivos totalmente voltados para que a pessoa com deficiência tivesse sua dignidade humana preservada, bem como tivesse acesso não só à educação, mas também amparo em outras áreas, como acessibilidade, reabilitação, acesso ao mundo do trabalho e reinserção em sociedade, para que pudessem ter efetivo direito de participação e igualdade na social.

Em 1988, foi promulgada a última Constituição, conhecida como "Constituição Cidadã", expressão utilizada por Ulysses Guimarães, diante de muitos avanços sociais, trazidos pela mesma, como observa José Afonso da Silva:

É a Constituição Cidadã, na expressão de Ulysses Guimarães, Presidente da Assembleia Nacional Constituinte que a produziu, porque teve ampla participação popular em sua elaboração e especialmente porque se volta decididamente para a plena realização da cidadania (SILVA, 2010, p. 90).

Ao tratar da educação, cultura e desporto, a "Constituição Cidadã", disciplinou nos artigos 205 a 214, a educação como um direito social, universal e de responsabilidade do Estado e da família. Foi baseada em parâmetros mundiais, sobre a proteção das pessoas com deficiência, representando um marco na defesa do princípio da igualdade (artigo $5^{\circ}$, caput), e outros dispositivos de proteção específica no artigo $7^{\circ}$, inciso XXXI; artigo 37, inciso VIII; artigo 203, incisos IV e V, artigo 227, inciso II, $\S 2^{\circ}$, dessa mesma constituição (BRASIL. Constituição da República Federativa do Brasil, 1988).

$\mathrm{Na}$ área da educação especial, o inciso III do artigo 208, disciplina ser responsabilidade do Estado ofertar "atendimento educacional especializado aos portadores de deficiência, preferencialmente na rede regular de ensino", diferenciando-se de algumas constituições passadas, que colocavam a família como responsável e o Estado em mera posição de colaborador. (BRASIL. Constituição da República Federativa do Brasil, 1988).

Destarte esse breve histórico, que a inclusão como um todo, demorou a ser contemplada pela legislação constitucional, sendo a história das pessoas com deficiência e a luta por seus direitos, marcada pela exclusão, segregação e integração, diante do âmbito jurídico e social.

\section{UMA ANÁLISE HISTÓRICA DAS GARANTIAS LEGAIS SOBRE OS DIREITOS DA PESSOA COM DEFICIÊNCIA NO PROCESSO EDUCACIONAL.}

A inclusão, atualmente, é resultado de longos debates no meio educacional, principalmente no âmbito das políticas públicas, além da criação e consolidação de legislações nacionais e internacionais que assegurem, normatizem e garantam a educação como direito de todas as pessoas.

Góes e Laplane (2013, p.02) destacam que, "o sistema escolar alinha-se com a legislação internacional e com posturas mais avançadas em relação aos direitos sociais, mas por outro lado, sua ação é limitada no sentido de viabilizar concretamente as políticas inclusivas".

Isto é, tudo está a corroborar para que a inclusão em sociedade ocorra de maneira efetiva, por estar em sintonia com a legislação e os direitos humanos, porém, somente esses elementos não são suficientes e agem de maneira limitada, não rompendo com todas as barreiras necessárias para que que esse processo seja incisivo de fato na vida do cidadão.

O direito à educação, com o advento da Constituição Federal de 1988, passou a ser de direito público subjetivo, tendo seu acesso garantido a todos, conforme disciplina o artigo 205 da mesma Constituição (BRASIL. Constituição da República Federativa do Brasil, 1988).

Além disso, a Constituição Cidadã, como é conhecida a Carta Magna de 1988, dedicou um capitulo apenas para a educação (capítulo III, art. 205 a 214), cabe também ressaltar o aparato que a 
inclusão social tem nos princípios constitucionais, como o princípio da igualdade e da dignidade da pessoa humana.

O princípio da dignidade da pessoa humana é dispositivo fundamental no Estado Democrático de Direito, passando a figurar também na Constituição Federal de 1988, em seu art. $1^{\circ}$. O doutrinador Sérgio Ferraz, afirma sobre esse princípio:

[...] é base da própria existência do Estado brasileiro e, ao mesmo tempo, fim permanente de todas as suas atividades. É a criação e manutenção das condições para que as pessoas sejam respeitadas, resguardadas e tuteladas, em sua integridade física e moral, assegurados o desenvolvimento e a possibilidade da plena concretização de suas potencialidades e aptidões (FERRAZ, 1991, p. 19).

Da mesma forma, o princípio da igualdade também é fundamental para a cidadania e a efetividade do Estado Democrático de Direito, sendo amplamente tratado na Constituição Brasileira, nos incisos III e IV do artigo $3^{\circ}$ e do artigo $5^{\circ}$ :

Art. $3^{\circ}$ : Constituem objetivos fundamentais da República Federativa do Brasil:

III - erradicar a pobreza e a marginalização e reduzir as desigualdades sociais e regionais;

IV- promover o bem de todos, sem preconceito de origem, raça, sexo, cor, idade e quaisquer outras formas de discriminação (BRASIL. Constituição da República Federativa do Brasil, 1988).

Art. $5^{\circ}$. Todos são iguais perante a lei, sem distinção de qualquer natureza, garantindo-se aos brasileiros e aos estrangeiros residentes no País a inviolabilidade do direito à vida, à liberdade, à igualdade, à segurança e à propriedade [...] (BRASIL. Constituição da República Federativa do Brasil, 1988).

Esses princípios sãos elencados em conjunto com os Direitos e Garantias Fundamentais da Constituição Brasileira, que trazem valores primordiais para sistematizar e regular a vida social, política e jurídica de todo o cidadão brasileiro.

A Lei de Diretrizes e Bases da Educação Nacional de 1961 (1ª versão), mencionava a pessoa com deficiência, mas não de forma plena, vejamos: "A Educação de excepcionais, deve, no que for possível, enquadrar-se no sistema geral de Educação, a fim de integrá-los na comunidade" (BRASIL, lei $\left.n^{\circ} 4.024 / 1961\right)$.

Vemos nitidamente nesse artigo, sendo positivada umas das fases pela qual passou o processo de inclusão, a "integração". Tal artigo deixa claro que a pessoa com deficiência seria integrada à educação e não inclusa, o Estado não se preocupou em pensar de que maneira o indivíduo viria a integrar um espaço sem adaptações para recebe-lo, fez questão apenas de dizer que ofertou o direito desse de estar presente, mesmo sem oferecer nenhum subsídio.

A segunda versão da LDB, foi sancionada no período da ditadura militar, em 1971 e substituiu a versão anterior. Em seu bojo, ela traça sobre a educação de pessoas com deficiência, o seguinte: os alunos com "deficiências físicas ou mentais, os que se encontrem em atraso considerável quanto à idade regular de matrícula e os superdotados deverão receber tratamento especial" (BRASIL, lei n 5692/1971).

Porém, não era contemplado o direito a inclusão na escola regular, mas apenas a determinação de um lugar especial para a educação dessas crianças, o que viria a ser a segregação, novamente.

Muitos aparatos legais tentaram buscar e garantir a legalidade de uma "educação para todos", mesmo que até então, sem sucesso. Verifica-se que a atual Lei de Diretrizes e Bases da Educação (LDB), em sua $3^{\text {a }}$ e atual versão, lei no 9394/96, apresenta seus princípios e fins, onde, segundo o art. $3^{\circ}$ dessa lei, deverá observar os seguintes parâmetros:

Art. $3^{\circ} \mathrm{O}$ ensino será ministrado com base nos seguintes princípios:

I - igualdade de condições para o acesso e permanência na escola;

II - liberdade de aprender, ensinar, pesquisar e divulgar a cultura, o pensamento, a arte e o saber;

III - pluralismo de ideias e de concepções pedagógicas;

IV - respeito à liberdade e apreço à tolerância; [...] (BRASIL, lei nº 9394/96).

Segundo o artigo acima, a educação básica terá como pilares os princípios descritos pela LDB de 1996, garantindo a igualdade no acesso à educação para todos os cidadãos brasileiros, devendo respeitar as liberdades de aprendizado de cada educando, bem como seus ideais, a diversidade e a pluralidade de ideias.

Nesse prisma, segundo a legislação, o ensino deve ser amplo para todos, sendo que, para isso é fundamental que as políticas públicas estejam articuladas com os objetivos, afim de que se garanta a inclusão efetiva em todos os sujeitos do sistema educacional. Além disso, tais medidas devem ser 
fiscalizadas por toda população para que sejam cobradas adaptações curriculares na rede regular de ensino e atendimento educacional especializado para aqueles que necessitem (CARVALHO; SILVA, 2012).

As políticas públicas têm o intuito de pleitear espaço para os investimentos sociais, voltados ao desenvolvimento responsável e inclusão na sociedade. Isso implica na necessidade de haver políticas integradas para à educação e formação profissional de todos os cidadãos.

Para o aprofundamento desse estudo é pertinente destacar sobre a transversalidade, conforme os Parâmetros Curriculares Nacionais: "uma educação transversal diz respeito à possibilidade de se estabelecer, na prática educativa, uma relação entre aprender conhecimentos teoricamente sistematizados e as questões da vida real e a sua transformação" (BRASIL, PCNs/1998).

Isto é, além dos conteúdos ofertados pela escola, a educação deve ser transversal, no sentido de sempre estar levando em consideração questões concretas e realidades vividas por cada indivíduo, para que de fato haja mudança, sendo esse um processo conjunto.

A respeito do Atendimento Educacional Especializado (AEE), deverá ser ofertado gratuitamente, como prevê o artigo $4^{\circ}$ da LDB, inciso III:

Art. $4^{\circ} \mathrm{O}$ dever do Estado com educação escolar pública será efetivado mediante a garantia de:

III - atendimento educacional especializado gratuito aos educandos com deficiência, transtornos globais do desenvolvimento e altas habilidades ou superdotação, transversal a todos os níveis, etapas e modalidades, preferencialmente na rede regular de ensino (BRASIL, lei nº 9394/96).

O AEE é estruturado para apoiar o desenvolvimento do educando com deficiência, sendo realizado com intermédio de profissionais com capacitações específicas da área de inclusão educacional, todavia, esse atendimento deve ser realizado em contraturno ao do ensino regular, não substituindo esse último, pois trata-se de uma das modalidades de ensino positivadas na legislação.

Sobre isso, a Política Nacional de Educação Especial estabelece:

$\mathrm{O}$ atendimento educacional especializado tem como função identificar, elaborar e organizar recursos pedagógicos e de acessibilidade que eliminem as barreiras para a plena participação dos estudantes, considerando suas necessidades específicas. As atividades desenvolvidas no atendimento educacional especializado diferenciam-se daquelas realizadas na sala de aula comum, não sendo substitutivas à escolarização. Esse atendimento complementa e/ou suplementa a formação dos estudantes com vistas à autonomia e independência na escola e fora dela (BRASIL. Política Nacional de Educação Especial na Perspectiva da Educação Inclusiva, 2008, p.03).

É perceptível perceber que a legislação, que diz respeito à educação especial, é bastante ampla, além de ser um assunto em pauta social, porém, é preciso analisar se de fato esses direitos estão sendo efetivados para as pessoas que necessitam deles, assegurando a oportunidade de todos a participarem de uma sociedade justa, com dignidade, igualdade e equidade, dentro e fora do ambiente escolar.

\section{A INFLUÊNCIA DAS LEGISLAÇÕES INTERNACIONAIS NA INCLUSÃO SOCIAL EDUCACIONAL NO BRASIL}

A Declaração Universal dos Direitos Humanos, foi um documento produzido por representantes de diferentes seguimentos, do mundo todo, sendo proclamada pela Assembleia Geral das Nações Unidas em Paris, no dia 10 de dezembro de 1948, por meio da Resolução 217 A (III) da Assembleia Geral, onde pela primeira vez houve um documento de proteção universal dos direitos humanos. Em seu artigo I, já era garantido que "todas as pessoas nascem livres e iguais em dignidade e direitos" (ONU, 1948).

A inclusão social foi tema em diversas conferências internacionais, tais quais podemos citar: a Conferência Mundial de Educação para Todos, no ano de 1990 em Jomtien (Tailândia), sendo resultado dessa a Declaração Mundial sobre Educação para Todos; a Conferência Mundial sobre Necessidades Educativas Especiais, realizada em 1994 em Salamanca (Espanha) com a cooperação da UNESCO; e a Convenção Internacional sobre os Direitos das Pessoas com Deficiência e seu Protocolo Facultativo.

A Declaração Mundial sobre Educação para Todos - Satisfação das Necessidades Básicas de Aprendizagem, focou principalmente em defender que a educação é um direito fundamental de todos os cidadãos, sem qualquer distinção de gênero, cor, raça e idade (UNESCO, 1990).

Essa afirmação já se encontrava dentro do sistema jurídico brasileiro, mesmo antes de tal declaração, vindo assim, a amparar ainda mais tal questão, pois, o princípio da igualdade repudia qualquer 
modo de discriminação e fora inserido na Constituição de 1988, como fora mencionado anteriormente neste trabalho.

A Declaração, pontuou também que a educação seria o modo como o indivíduo poderia conquistar seus objetivos, levando em consideração um meio ambiente mais equilibrado, em sintonia com a evolução econômica, social e cultural com cooperação internacional. Cita como objetivos satisfazer necessidades básicas da aprendizagem e enriquecer valores culturais e morais do indivíduo (UNESCO, 1990).

Na Espanha, 113 órgãos, dentre eles presentes 88 governos e 25 entidades internacionais, aprovaram a Declaração de Salamanca, onde teve como princípio norteador o "dever das escolas de acolher todas as crianças, independentemente de suas condições físicas, intelectuais, sociais, emocionais, linguísticas ou outras" (BRASIL, Declaração de Salamanca e linhas de ação sobre necessidades educativas especiais, 1994).

A Declaração de Salamanca, foi elaborada na Conferência Mundial sobre Educação Especial, no intuito de sedimentar diretrizes bases para elaboração de reformas políticas nos sistemas educacionais de acordo com o movimento internacional sobre inclusão social e educação especial.

Segundo Menezes (2001), Salamanca é considerada um dos principais documentos sobre inclusão, juntamente com a Convenção de Direitos da Criança (1988) e com a Declaração sobre Educação para Todos de 1990, sendo resultado de uma disposição mundial que fortaleceu a educação inclusiva, cujo a origem é atribuída aos movimentos provocados pelos direitos humanos e pela desconstituição manicomial, que surgiu nas décadas de 60 e 70.

De acordo com a Declaração, princípios e projetos da escola devem se adequar ao indivíduo que nela está matriculado, conforme o art.11: "O planejamento educativo elaborado pelos governos deverá concentrar-se na educação para todas as pessoas em todas as regiões do país e em todas as condições econômicas, através de escolas públicas e privadas" (DECLARAÇÃO DE SALAMANCA, 1994, p. 1718).

Destarte o texto acima, pode-se perceber que a Declaração de Salamanca, no rol dos diretos, torna iguais todos os indivíduos no que tange ao direito à educação universal e também de qualidade, no acesso ao ensino. Na sua escrita, a Declaração se inicia com a seguinte proposta:

O direito de todas as crianças à educação está proclamado na Declaração Universal dos Direitos Humanos e foi reafirmado com veemência pela Declaração sobre Educação para Todos. Pensando desta maneira é que este documento começa a nortear Todas as pessoas com deficiência têm o direito de expressar os seus desejos em relação à sua educação. Os pais têm o direito inerente de ser consultados sobre a forma de educação que melhor se adapte às necessidades, circunstâncias e aspirações dos seus filhos. (Declaração de Salamanca, 1994, p. 5 - 6).

Nesse paradigma, para a escola ser considerada inclusiva, ela deve integralmente acolher toda comunidade, com responsabilidade, inclusive com profissionais qualificados em diversas áreas educativas, sendo interdisciplinares, pensando sempre no indivíduo que dela usufruirá. Desse modo, conforme o seu próprio texto atesta, a conferência de Salamanca contribuiu da seguinte forma:

Proporcionou uma oportunidade única de colocação da educação especial dentro da estrutura de “educação para todos” firmada em 1990 (...) Ela promoveu uma plataforma que afirma o princípio e a discussão da prática de garantia de inclusão das crianças com necessidades educacionais especiais nestas iniciativas e a tomada de seus lugares de direito numa sociedade de aprendizagem. (UNESCO/Ministry of Education and Science -Spain, 1994, p. 15).

Essa afirmação, vai ao encontro novamente do artigo $5^{\circ}$ da Constituição Federal de 1988 , onde todos os indivíduos devem ter tratamento igualitário, bem como em consonância com o artigo 205 da mesma Constituição, onde o ensino deve ser universal, sem qualquer forma de distinção, estando assim de acordo com a política de educação inclusiva, sendo a Declaração de Salamanca, recepcionada pela Constituição vigente.

Em 2007, foi realizada a Convenção sobre os Direitos das Pessoas com Deficiência e o respectivo Protocolo Facultativo, sendo que esse documento já era mais focalizado e abrangente que os anteriores, sendo assinado pelo Brasil em 2007.

Em 25 de agosto de 2009, consolidando o que acima foi dito, o governo brasileiro, oficialmente comprometeu-se a cumprir em todo território nacional à Convenção Internacional sobre os Direitos das Pessoas com Deficiência e seu Protocolo Facultativo, assinados em Nova York, em 30 de março de 2007, por meio do Decreto $n^{\circ} 6.949 / 2009$. 
Com um olhar hermenêutico, tanto sobre a Convenção, como da postura do governo brasileiro, percebe-se que o Estado se baseou em normas internacionais, no que diz respeito a sua política de inclusão social, com objetivo de assegurar as pessoas com deficiência todos os seus direitos como cidadãos brasileiros, além de assumir essa responsabilidade para si.

Em 2011, a Secretaria dos Direitos Humanos, publicou uma cartilha, contendo na íntegra a Convenção Internacional sobre os Direitos das Pessoas com Deficiência e seu Protocolo Facultativo e reafirmou os compromissos do Estado em cumpri-la.

Com certeza, tudo isso foi motivo de muita comemoração para toda comunidade que há anos luta pelos direitos da pessoa com deficiência, deixando o Brasil em consonância com toda ordem internacional a respeito da inclusão social e educação especial.

\section{AS INOVAÇÕES COMTEMPLADAS NA LBI (LEI 13.146/2015)}

Em 2015, foi sancionada no Brasil a Lei Brasileira de Inclusão, depois de mais de treze anos de tramitação no Congresso Nacional, passando a ser um marco legislativo para a proteção dos direitos da pessoa com deficiência.

Esse estatuto possui 127 artigos e quase trezentos novos dispositivos, que em conjunto alteram o ordenamento jurídico no que trata sobre inclusão e educação especial no país, além de estar de acordo com conceitos internacionais sobre deficiência, o art. $2^{\circ}$, disciplina sobre isso:

Art. 2º. Considera-se pessoa com deficiência aquela que tem impedimento de longo prazo de natureza física, mental, intelectual ou sensorial, o qual, em interação com uma ou mais barreiras, pode obstruir sua participação plena e efetiva na sociedade em igualdade de condições com as demais pessoas (BRASIL, lei no 13.146).

$\mathrm{O}$ artigo acima, conceitua o que seria a deficiência, no sentido de romper com paradigmas de que a pessoa com deficiência seria apenas aquela que necessita de adaptações físicas, aos olhos da sociedade. Além disso, deixa também explicito que o indivíduo que tenha algum impedimento mesmo que momentâneo, a ponto de o impedir de participar da sociedade em igualdade com os demais, será considerado pessoa com deficiência.

A partir dos estudos da LBI (Lei Brasileira de Inclusão), pode-se apontar que a mesma consiste em grande avanço com relação ao acesso à educação das pessoas com deficiência, pois assim, tem-se um aparato legal para sustentar reivindicações por oportunidades iguais em todas as esferas sociais, da qual o indivíduo com deficiência está inserido (PEREIRA; MOURA; ALBUQUERQUE, 2017).

A LBI, garante o direito à educação da pessoa com deficiência inclusive no ensino superior, tratando em seu art. 30:

Art. 30. Nos processos seletivos para ingresso e permanência nos cursos oferecidos pelas instituiçõos de ensino superior e de educação profissional e tecnológica, públicas e privadas, devem ser adotadas as seguintes medidas:

I - atendimento preferencial à pessoa com deficiência nas dependências das Instituições de Ensino Superior (IES) e nos serviços;

II - disponibilização de formulário de inscrição de exames com campos específicos para que o candidato com deficiência informe os recursos de acessibilidade e de tecnologia assistiva necessários para sua participação;

III - disponibilização de provas em formatos acessíveis para atendimento às necessidades específicas do candidato com deficiência;

IV - disponibilização de recursos de acessibilidade e de tecnologia assistiva adequados, previamente solicitados e escolhidos pelo candidato com deficiência;

$\mathrm{V}$ - dilação de tempo, conforme demanda apresentada pelo candidato com deficiência, tanto na realização de exame para seleção quanto nas atividades acadêmicas, mediante prévia solicitação e comprovação da necessidade;

VI - adoção de critérios de avaliação das provas escritas, discursivas ou de redação que considerem a singularidade linguística da pessoa com deficiência, no domínio da modalidade escrita da língua portuguesa;

VII - tradução completa do edital e de suas retificações em Libras. 
Nesse sentido, descrito acima, é garantido para a pessoa com deficiência o atendimento específico e especializado, em processos seletivos para ingresso em cursos superiores, profissionalizantes e tecnólogos, em instituições públicas e privadas.

Cabe ressaltar que, o educador que trabalha com pessoas que tem alguma necessidade especial, deverá realizar atividades educacionais adaptadas que valorizem as habilidades que este aluno da educação inclusiva já possui ou que desenvolva este educando, condicionando a flexibilização da ação pedagógica nas áreas do conhecimento.

Diante do exposto, a Lei Brasileira de Inclusão traz uma importante contribuição quando expressa no art. 27:

Art. 27. A educação constitui direito da pessoa com deficiência, assegurados sistema educacional inclusivo em todos os níveis e aprendizado ao longo de toda a vida, de forma a alcançar o máximo desenvolvimento possível de seus talentos e habilidades físicas, sensoriais, intelectuais e sociais, segundo suas características, interesses e necessidades de aprendizagem (BRASIL, lei $n^{\circ}$ 13.146).

O artigo acima citado, enfatiza o que a Constituição Federal de 1988 disciplinou em seu art. 205: "A educação, direito de todos" (BRASIL. Constituição da República Federativa do Brasil, 1988). Porém, o artigo não apenas enfatizou esse direito como também trouxe outras prerrogativas, assegurou a educação em todos os níveis de ensino, determinando que haja um sistema educacional totalmente inclusivo, valendo-se do respeito e do desenvolvimento máximo das capacidades e potencialidades do indivíduo.

Com o advento da LBI, tiveram-se avanços significativos para a pessoa com deficiência na sociedade em geral, podemos destacar algumas inovações importantes, como por exemplo: tornar crime atitudes que forem discriminatórias e preconceituosas, traz contribuições para a cidadania ao tratar de questões como a acessibilidade, criminalizando quem não a promover, dentre outros avanços que ainda não estavam previstos em lei (COSTA; RODRIGUES, 2017).

No que diz respeito a criminalização para quem discrimina a pessoa com deficiência, vejamos o art. 88 da LBI/2015:

Art. 88. Praticar, induzir ou incitar discriminação de pessoa em razão de sua deficiência:

Pena - reclusão, de 1 (um) a 3 (três) anos, e multa.

$\S 1^{\text {o }}$ Aumenta-se a pena em $1 / 3$ (um terço) se a vítima encontrar-se sob cuidado e responsabilidade do agente.

$\S 2^{\circ}$ Se qualquer dos crimes previstos no caput deste artigo é cometido por intermédio de meios de comunicação social ou de publicação de qualquer natureza:

Pena - reclusão, de 2 (dois) a 5 (cinco) anos, e multa.

$\S 3^{\circ} \mathrm{Na}$ hipótese do $\S 2^{\circ}$ deste artigo, o juiz poderá determinar, ouvido o Ministério Público ou a pedido deste, ainda antes do inquérito policial, sob pena de desobediência:

I - recolhimento ou busca e apreensão dos exemplares do material discriminatório;

II - interdição das respectivas mensagens ou páginas de informação na internet.

$\S 4^{\circ} \mathrm{Na}$ hipótese do $\S 2^{\circ}$ deste artigo, constitui efeito da condenação, após o trânsito em julgado da decisão, a destruição do material apreendido (BRASIL, lei $\mathrm{n}^{\circ}$ 13.146).

Essa conquista foi muito comemorada pela sociedade, pois é resultado de anos de lutas pelos Direitos Humanos, fazendo jus a milhões de brasileiros. A sanção transforma o estatuto em uma norma de comportamento de afirmação de direitos em uma sociedade repleta de estereótipos e padrões a serem seguidos, caminhando, ainda que morosamente, para a equidade.

A respeito da inclusão escolar, a LBI /2015, além das garantias já asseguradas na Constituição Federal de 1988 e na LDB/1996, disciplina também que as escolas particulares recebam estudantes com deficiência em sua sala de aula, e, que estes alunos com necessidades especiais, recebam as devidas adaptações no ambiente escolar sem nenhum custo a mais por parte das famílias. Sendo assim, é perceptível que a inclusão deixa de ser apenas dever da rede pública e passa a ser também da rede privada, garantindo direitos sociais e educacionais para a pessoa com deficiência (COSTA; RODRIGUES, 2017).

Podemos observar que com a LBI, todas as instituições passam a fazer parte do processo inclusivo na sociedade, reunindo boa parte dos aspectos da inclusão em um só documento, obedecendo a um dos pilares da educação, que é formar cidadãos que se respeitem mutuamente, levando em consideração as individualidades de cada um, diferenças e culturas. 


\section{CONSIDERAÇÕES FINAIS}

Em linhas gerais, a meta essencial do processo de inclusão social é acolher as pessoas em uma sociedade da qual elas nunca fizeram parte até então, visando reduzir as disparidades para que cada vez mais pessoas tenham uma condição de vida digna, valendo-se do princípio da igualdade e dignidade da pessoa humana, promovendo acesso equitativo aos benefícios do desenvolvimento.

Nesse viés, a inclusão deve acolher o indivíduo em sociedade, não apenas no ambiente escolar, mas sim em todas as esferas sociais, sem discriminação a respeito de deficiência, aspectos socioemocionais, intelectuais, linguísticos, gênero, orientação sexual, cor, religião, culturas e quaisquer outras.

Ao longo do trabalho, percebe-se que foram anos de luta, desde a exclusão, segregação, integração até a inclusão social. Porém, é difícil dizer que a inclusão está de fato consolidada, pois o processo de mudanças exige ser constante e de estar sempre em mutação. Para tanto, não basta apenas positivar leis, são necessários investimentos para que haja de fato efetividade do que determinam essas normas, bem como executar também as penalidades para aqueles que as descumprirem.

É um trabalho conjunto entre Estado e sociedade, onde o primeiro deve investir em políticas públicas e capacitação de profissionais, e, a última, deve fiscalizar e exigir que seus direitos sejam resguardados. Mas, vale ressaltar, que também devem ocorrer mudanças em seu comportamento atitudinal, principalmente no que tange ao preconceito, discriminação e desrespeito em relação a pessoa com deficiência.

A comunidade aclama e vangloria por todos os direitos conquistados após anos de luta, na área da educação, mercado de trabalho e em muitas outras, mas sabemos que ainda será preciso muito mais para que de fato a verdadeira "inclusão social" deixe de ser apenas utopia e passe a ser realidade na vida de todos os cidadãos, como preconiza a legislação, fazendo jus a nossa Constituição.

\section{REFERÊNCIAS}

ARAÚJO, Luiz Alberto David. A proteção constitucional das pessoas portadoras de deficiência. 2. ed. Brasília: Coordenadoria Nacional para Integração da Pessoa Portadora de Deficiência - CORDE, 1997, p.60.

BASTOS, Celso Ribeiro. Curso de Direito Constitucional. São Paulo: Celso Bastos Editora, 2002, p. 159.

BRASIL, Ministério da Educação. Lei de Diretrizes e Bases da Educação Nacional. LDB 4.024, de 20 de dezembro de 1961.

, Ministério da Educação. Lei de Diretrizes e Bases da Educação Nacional. LDB 5.692, de 11 de agosto de 1971.

Ministério da Educação. Lei de Diretrizes e Bases da Educação Nacional. LDB 9.394, de 20 de dezembro de 1996.

Ministério da Educação. Parâmetros Curriculares Nacionais. Secretaria da Educação Fundamental. MEC/SEF, 1998.

Constituição da República dos Estados Unidos do Brasil, de 24 de fevereiro de 1891.

Constituição da República dos Estados Unidos do Brasil, de 16 de julho de 1934.

, Constituição dos Estados Unidos do Brasil, de 10 de novembro de 1937.

, Constituição dos Estados Unidos do Brasil, de 18 de setembro de 1946.

, Constituição da República Federativa do Brasil, de 24 de janeiro de 1967. 
, Emenda Constitucional $\mathbf{n}^{\circ}$ 01, de 17 de outubro de 1969. In: Diário Oficial da União, Brasília, 30 out. 1969.

Emenda Constitucional $\mathbf{n}^{\circ} \mathbf{1 2}$, de 17 de outubro de 1978. Assegura aos Deficientes a melhoria de sua condição social e econômica. In: Diário Oficial da União, Brasília, 12 out. 1978.

outubro de 1988

Constituição da República Federativa do Brasil. Brasília: Imprensa Oficial, de 05 de

Declaração de Salamanca e linha de ação sobre necessidades educativas especiais. Brasília: UNESCO, 1994.

Decreto $\mathbf{n}^{\circ}$ 6.949, de 25 de agosto de 2009. - 4. ed., rev. e atual. - Brasília: Secretaria de Direitos Humanos, Secretaria Nacional de Promoção dos Direitos da Pessoa com Deficiência, 2011.

Lei 13146 - LBI - Lei Brasileira de Inclusão da Pessoa com Deficiência. Disponível em: http://www.planalto.gov.br/ccivil_03/_ato2015-2018/2015/Lei/L13146.htm Acesso em: 03 mar. 2020.

CARVALHO, José Raimundo de. SILVA e Miola da. O Princípio da Dignidade Humana e o Direito à Inclusão Social. Revista Jurídica. Ano XII. n. 18. 2012, Jan.-Jun., Anápolis/GO. Uni. EVANGÉLICA. Disponível em: periodicos.unievangelica.edu.br/index.php/revistajuridica/article/view/411/410. Acesso em: 06 nov. 2019.

COSTA, Vanderlei Balbino da. RAMOS Vania Rodrigues. Novos horizontes sobre inclusão escolar: múltiplos olhares. Curitiba: CRV, 2017.

FERRAZ, Sergio. Manipulações biológicas e princípios constitucionais: uma introdução. Porto Alegre. S. A. Fabris. 1991.

GÓES, M. C. R. LAPLANE, A. L. F. Políticas e práticas de Educação Inclusiva. 4.ed. rev.- CampinasSP: Autores Associados, 2013.

GUGEL, Maria Aparecida. Pessoas com Deficiência e o Direito ao Trabalho. Florianópolis. Obra Jurídica, 2007. Disponível em:

http://www.ampid.org.br/ampid/Artigos/PD_Historia.php. Acesso em: 06 jan. 2020.

PEREIRA, Larissa Rebouças; MOURA, Larissa Feitosa; ALBUQUERQUE, Eugênia Morais de. A Inclusão de alunos com necessidades especiais na educação regular. Universidade Federal Rural do Semi-Árido Coordenação Geral de Ação Afirmativa, Diversidade e Inclusão Social. Disponível em: http://periodicos.ufersa.edu.br/revistas/index.php/includere ISSN 2359-5566. Acesso em: 06 abr. 2020

SILVA, José Afonso da. Curso de Direito Constitucional Positivo. 33. ed. São Paulo: Malheiros Editores, 2010, p. 82; 90

MANTOAN, Maria Teresa Eglér. A educação especial no Brasil - da exclusão à inclusão escolar. Universidade Estadual de Campinas. Faculdade de Educação. Laboratório de Estudos e Pesquisas em Ensino e Diversidade - $\quad$ LEPED/Unicamp Disponível em: http://www.lite.fe.unicamp.br/cursos/nt/ta1.3.htm. Acesso em: 04 fev. 2020.

MAZZOTA, Marcos José Silveira. Educação Especial no Brasil: História e políticas públicas. São Paulo: Cortez, 1996.

MAZZOTA, Marcos José Silveira. Educação Especial no Brasil História e Políticas Públicas, $5^{\text {a }}$ edição. São Paulo. Cortez Editora. 2005.

MELO, Francisca Oliveira da Silva. A história da educação especial rumo à inclusão: Um desafio a conquistar. Publicado em 17 de June de 2011. Disponível em: https://www.webartigos.com/artigos/a- 
historia-da-educacao-especial-rumo-a-inclusao-um-desafio-a-conquistar/68960\#ixzz5EH2ueKWI. Acesso em: 07 jan. 2020.

MENEZES, Ebenezer Takuno de; SANTOS, Thais Helena dos. Verbete Declaração de Salamanca. Dicionário Interativo da Educação Brasileira - Educabrasil. São Paulo: Midiamix, 2001. Disponível em: <http://www.educabrasil.com.br/declaracao-de-salamanca/>. Acesso em: Acesso em: 05 jan. 2020.

MRECH, L. M. O que é educação inclusiva? Revista Integração. Brasília, ano 08, n. 20, p. 37-39, 1998.

ORGANIZAÇÃO DAS NAÇÕES UNIDAS (ONU). Convenção sobre os direitos das pessoas com deficiência, 2007. Disponível em: Acesso em: 15 dez. 2019.

ORGANIZAÇÃO DAS NAÇÕES UNIDAS (ONU). Declaração Universal Dos Direitos Humanos. Assembleia Geral das Nações Unidas em Paris. 10 dez. 1948. Disponível em: http://www.direitoshumanos.usp.br/index.php/Declaração-Universal-dos-Direitos-Humanos/declaracaouniversal-dos-direitos-humanos.html. Acesso em: 02 de jan. 2020.

SASSAKI, R. Kazumi. Inclusão, construindo uma sociedade para todos. 5 ed. Rio de Janeiro. Editora WVA. 1997.

UNESCO, Declaração mundial sobre educação para todos: satisfação das necessidades básicas de aprendizagem. Jomtien, 1990, p.08.

UNESCO/Ministry of Education and Science (1994) Final Report on the World Conference on Special Needs Education: Access and Quality. Salamanca, Spain, 7-10 June, 1994.

Informações sobre os autores: VAP: Especialista em Libras - Educação Especial pela Faculdade FAEL (2019). Graduada em Pedagogia pela Universidade Estácio de Sá (2017). Bacharel em Direito pela Faculdade FAMP (2018). Professora/intérprete no Colégio Prof. ${ }^{a}$ Alice - C.E.P.A.P.A, Mineiros-GO (2014) e Professora no Centro Universitário de Mineiros-UNIFIMES (2019). E-mail: vanessa.alves@unifimes.edu.br

Contribuição dos autores: VAP: conceitualização, captação de recursos, supervisão, redação. 